\title{
Stochastic extension of cellular manufacturing systems: a queuing-based analysis
}

\author{
Fatemeh Fardis ${ }^{1}$, Afagh Zandi ${ }^{1}$ and Vahidreza Ghezavati ${ }^{*}$
}

\begin{abstract}
Clustering parts and machines into part families and machine cells is a major decision in the design of cellular manufacturing systems which is defined as cell formation. This paper presents a non-linear mixed integer programming model to design cellular manufacturing systems which assumes that the arrival rate of parts into cells and machine service rate are stochastic parameters and described by exponential distribution. Uncertain situations may create a queue behind each machine; therefore, we will consider the average waiting time of parts behind each machine in order to have an efficient system. The objective function will minimize summation of idleness cost of machines, sub-contracting cost for exceptional parts, non-utilizing machine cost, and holding cost of parts in the cells. Finally, the linearized model will be solved by the Cplex solver of GAMS, and sensitivity analysis will be performed to illustrate the effectiveness of the parameters.
\end{abstract}

Keywords: Cellular manufacturing system; Stochastic arrival rate and service rate; Average waiting time; Queuing theory

\section{Introduction}

Cellular manufacturing system (CMS) is an application of the group technology concept, which classifies parts with closest features and processes into the part families and assigns machines into the cells, with the goal of increasing production efficiency while decreasing the unit cost. Some advantages of CMS such as simplification of material flow, reduction of transportation and queuing times, reduction of material handling cost and setup times, and the increase of machine utilization and throughput rates are declared in literatures (Muruganandam et al. 2005; Olorunniwo and Udo 2002; Wemmerlov and Hyer 1989). The four major decisions in the implementation of cellular manufacturing systems are the following:

1. Cell formation: grouping parts with the similar processes and features into part families and allocating machines to the cells (Mahdavi et al. 2007; Muruganandam et al. 2005; Yasuda et al. 2005)

\footnotetext{
* Correspondence: v_ghezavati@azad.ac.ir

${ }^{2}$ Faculty of Industrial Engineering, Islamic Azad University, South Tehran Branch, Tehran, Iran

Full list of author information is available at the end of the article
}

2. Group layout: laying out cells and machines within each cell (Mahdavi and Mahadevan 2008; TavakkoliMoghaddam et al. 2007; Wu et al. 2007a)

3. Group scheduling: operating and managing the cell operation (Mak and Wang 2002; TavakkoliMoghaddam et al. 2010)

4. Resource allocation: assigning resources, such as tools, materials, and human resources, to the cells Cesani and Steudel (2005; Mahdavi et al. 2010)

Wu et al. (2007b) considered cell formation, group layout, and group scheduling decisions simultaneously in their model, which minimize the makespan. They presented a hierarchical genetic algorithm to solve it. Logendran (1993) developed a mathematical programming model to minimize part inter-cell and intra-cell movements and proposed a heuristic algorithm to solve it. Chen (1998) proposed an integer programming model to minimize material handling and machine cost and reconfiguration cost to design a sustainable cellular manufacturing system in a dynamic environment. Most of the developed models in cellular manufacturing systems are cost-based, but there are some models in which machine reliability is considered simultaneously with different cost types. A multi-objective mixed 
integer programming model was presented by Das et al. (2006) that minimizes variable cost of machine and penalty cost of non-utilizing machine as well as inter-cell material handling cost, and maximizes system reliability with minimizing failure rate. Machine breakdown cost (Jabal-Ameli and Arkat 2007) and inverse of the reliability of the system (Das et al. 2007) are two more objective components in order to maximize machine reliability, which will develop cell performance.
Cellular manufacturing problems can be under static or dynamic conditions. In static conditions, cell formation is done for a single-period planning horizon, where product mix and demand rate are constant. However, in dynamic conditions, the planning horizon is considered as a multi-period planning horizon where the product mix and demand rate differ from one period to another. In order to reach the best efficiency, there will be different cell formations for each period. Some recent

Table 1 Summarized cellular manufacturing system review

\begin{tabular}{|c|c|c|c|c|}
\hline Publication & Objective & $\begin{array}{l}\text { Problem } \\
\text { definition }\end{array}$ & $\begin{array}{l}\text { Solution } \\
\text { method }\end{array}$ & Output \\
\hline Sarker and Li (1997) & Min INTER + OC & SO, MIP & $B \& B$ & $C F, P R$ \\
\hline Wicks and Reasor (1999) & Min INTER + RCC + Cl & SO, DP, MPP, MIP & GA & $C F, M D$ \\
\hline Chen (1998) & Min INTER + OC + MHC + RCC & SO, DP, MPP, IP & $\mathrm{DBH}$ & $C F, R C P$ \\
\hline Chen (2001) & Min INTER + OC + IC + SC & SO, MINLP & $\mathrm{SMH}$ & $C F, I L, P L$ \\
\hline Baykasoglu et al. (2001) & Min DS + CLV + ECR & $\mathrm{MO}, \mathrm{NLP}$ & SA & $C F, P R P$ \\
\hline Mak and Wang (2002) & Min TDT & SO, MINLP & GA & CF, PS \\
\hline Muruganandam et al. (2005) & Min CLV + MM & $\mathrm{CO}, \mathrm{NLP}$ & MA & $\mathrm{CF}$ \\
\hline Tavakkoli-Moghaddam et al. (2005) & Min RCC + MAC + OC + INTER & SO, DP, NLP & GA, SA, TS & $C F, R C P$ \\
\hline \multirow[t]{2}{*}{ Das et al. (2006) } & Min 1.FRM & \multirow[t]{2}{*}{$\mathrm{MO}, \mathrm{MIP}$} & \multirow[t]{2}{*}{ SA } & \multirow[t]{2}{*}{$C F, P R$} \\
\hline & 2.VCM + INTER + NUC & & & \\
\hline Chan et al. (2006) & Min VO + EE, TDT & SO, NLP, QAP, 2SP & GA & CF, MSE \\
\hline Saidi-Mehrabad and Safaei (2007) & Min MAC + INTER + OC + RCC & SO, DP, MPP, NLP & NA & $C F, C S, P R, R C P, M D$ \\
\hline Jabal-Ameli and Arkat (2007) & Min INTER + MBC & $\mathrm{SO}, \mathrm{IP}$ & $B \& B$ & $C F, P R$ \\
\hline Wu et al. (2007a) & Min 1.MM, 2.EE & $\mathrm{MO}, \mathrm{IP}$ & HGA & $C F, G L$ \\
\hline Wu et al. (2007b) & Min CM & SO, NLP & HGA & $C F, G L, P S$ \\
\hline \multirow[t]{2}{*}{ Das et al. (2007) } & Min 1.ISR & \multirow[t]{2}{*}{$\mathrm{MO}, \mathrm{NLP}$} & \multirow[t]{2}{*}{ HIA } & \multirow[t]{2}{*}{ CF, OPMI } \\
\hline & 2.VCM + INTER + NUC & & & \\
\hline Mahdavi et al. (2007) & Min EE + VO & $\mathrm{SO}, \mathrm{NLP}$ & $B \& B$ & $\mathrm{CF}$ \\
\hline Schaller (2007) & $\mathrm{Min} P C+M A C+R C C$ & SO, DP, IP & CBP, TS & $C F, R C P$ \\
\hline Safaei et al. (2008) & Min INTER + INTRA + CCM + VCM + RCC & SO, DP, MPP, MIP & MFA-SA & $C F, R C P$ \\
\hline \multirow[t]{2}{*}{ Bajestani et al. (2009) } & Min 1.CLV & \multirow[t]{2}{*}{ MO, DP, MINLP } & \multirow[t]{2}{*}{ MOSS } & \multirow[t]{2}{*}{$C F, R C P$} \\
\hline & 2.INTER + RCC + PUC & & & \\
\hline Kioon et al. (2009) & $\begin{array}{l}\text { Min RCC + PM + OC + SCC + HC + PC + INTER + } \\
\text { INTRA }\end{array}$ & SO, DP, MINLP & $B \& C$ & $C F, P P, P R, R C P, I L$ \\
\hline $\begin{array}{l}\text { Safaei and Tavakkoli-Moghaddam } \\
\text { (2009) }\end{array}$ & $\begin{array}{l}\text { Min } C C M+V C M+I T+I N T E R+I N T R A+R C C+ \\
\text { SCC }\end{array}$ & SO, DP, MINLP & $B \& B$ & $\mathrm{CF}, \mathrm{RCP}, \mathrm{BL}, \mathrm{IL}$ \\
\hline $\begin{array}{l}\text { Saidi-Mehrabad and Ghezavati } \\
\text { (2009) }\end{array}$ & Min ICM + SCC + NUC & SO, STP, MINLP & $B \& B$ & CF \\
\hline Mahdavi et al. (2010) & Min $V O+E E$ & SO, NLP & GA & CF \\
\hline (Tavakkoli-Moghaddam et al. 2010) & Min INTRAT $+\pi+C S C+C M$ & MC, MINLP & SS & CF, PS \\
\hline \multirow[t]{2}{*}{ Mahdavi et al. (2010) } & $\mathrm{Min} H C+\mathrm{BC}+$ INTER & \multirow[t]{2}{*}{ SO, DP, MPP, NLP } & \multirow[t]{2}{*}{$B \& B$} & $C F, R C P, W A, I L$ \\
\hline & $\mathrm{MC}+\mathrm{RCC}+\mathrm{SAC}+\mathrm{HIC}+\mathrm{FIC}$ & & & $\mathrm{PL}, \mathrm{BL}, \mathrm{MD}$ \\
\hline \multirow[t]{2}{*}{ Rafiee et al. (2011) } & Min INTER + INTRA & \multirow[t]{2}{*}{ SO, DP, MIP } & \multirow[t]{2}{*}{ PSO } & \multirow{2}{*}{$\begin{array}{l}C F, R C P, P R, P P, I L \\
S B Q\end{array}$} \\
\hline & $\mathrm{OC}+\mathrm{PUC}+\mathrm{RCC}+\mathrm{PRS}+\mathrm{SCC}+\mathrm{HC}+\mathrm{CRC}+\mathrm{PM}$ & & & \\
\hline Ariafar et al. (2011) & Min INTER + INTRA & SO, STP, MINLP & $B \& B$ & $G L$ \\
\hline
\end{tabular}


researches are under dynamic conditions (Kioon et al. 2009; Mahdavi et al. 2010; Schaller 2007).

Inputs of classical cellular manufacturing system problems are certain, but in real problems, some input parameters such as costs, demands, processing times, and setup times are uncertain so that this uncertainty can affect on the results. Some approaches such as stochastic programming, queuing theory, and robust optimization can be applied for uncertain models (Saidi-Mehrabad and Ghezavati 2009). Ariafar et al. (2011) proposed a mathematical model for layout problem in cellular manufacturing systems that the demand of each product was described by uniform distribution. The objective function of their model minimizes total cost of inter-cell and intra-cell material handling, concurrently. It was solved by the Lingo software. Saidi-Mehrabad and Ghezavati (2009) presented a stochastic CMS problem applying queuing theory approach. They assumed parts as customers and machines as servers, in which the arrival rate of parts and service rate of machines were identified by the exponential distribution. Their objective function components are the following: non-utilization cost, machine idleness cost, and sub-contracting cost. They computed the utilization factor for each machine which shows the probability that each machine is busy.

Table 1 illustrates the summarization of more reviewed literatures consisting objectives, model definitions, solution methods, and outputs. This helps to compare our work with previous researches. Table 2 describes the abbreviations used in Table 1 .

In this paper, we will develop a CMS problem as a queue system considering the average waiting time of parts behind each machine and holding cost of parts in cells. The goal of this model is to minimize summation of four cost types: (1) the idleness costs for machines, (2) total cost of sub-contracting, (3) non-utilization cost of machines in cells, and (4) holding cost of parts in cells. The rest of the paper is organized as follows: The proposed model is described in the 'Mathematical modeling' section. In the 'Experimental results' section, the experimental results and sensitivity analysis are presented. The last section is the 'Conclusions and future directions.'

\section{Mathematical modeling Problem description}

In this section, a stochastic cellular manufacturing system problem will be formulated as a queue system, which considers parts and machines as customers and servers with the arrival and service rate of $\lambda$ and $\mu$, respectively. Also, we consider that at each time, only one part can be processed by a machine; thus, when a machine is processing a part, the others should wait, and a queue will be created behind the machine. The population of this queue as a new part arrives (birth) can be increased, or it can be decreased (death) by service completion.

In a steady system, to avoid infinite growth of queue, the service rate must be greater than the arrival rate, so the utilization factor (probability of being busy) of each machine $(\rho=\lambda / \mu)$ will be less than 1 . Also, as each machine processes different parts with different arrival rates, according to this property, the minimum of some independent exponential random variables with the arrival rate of $\lambda_{1}, \lambda_{2}, \ldots, \lambda_{m}$ is also exponential with the arrival rate of $\lambda=\sum_{i=1}^{m} \lambda_{i}$. Hence, the utilization factor is $\rho=\sum \lambda_{i} / \mu$.

Our queue system is formulated as $M / M / 1$, where the arrival and processing time of parts are uncertain and described by exponential distribution, and as it was mentioned earlier, each machine can process at most one part at a time. In this problem, the decision maker needs to allocate parts and machines to cells in order to minimize objective function value. In the previous work of Saidi-Mehrabad and Ghezavati (2009), only the impact of utilization factor in designing CMS is considered, but our study shows the impact of utilization factor and maximum waiting time of parts simultaneously. Due to the uncertainty of arrival and service time of parts, the time that each part spends in the cell is uncertain, and as the time passes, the parts will be broken. Thus, in order to avoid long waiting time, a chance constraint is considered to show that the probability that the average waiting time of a part behind each machine exceeds the critical time is less than the service level $(\alpha)$. By knowing that, this probability affects on the utilization factor.

\section{Notation}

\section{Indexes}

The following are the indexes:

- $i \quad$ Part index, $i=1, \ldots, p$

- $j$ Machine index, $j=1, \ldots, m$

- $k$ Cell index, $k=1, \ldots, c$

- $\quad a_{i j}= \begin{cases}1 & \text { if machine } j \text { processes part } i \\ 0 & \text { otherwise }\end{cases}$

- $C_{i}$ Sub-contracting cost per unit for part $i$

- $u_{j}$ Idleness cost of machine $j$

- $M_{m}$ Maximum number of machines permitted in a cell

- $\quad \alpha$ Maximum allowed probability that the waiting time behind each machine can be more than the critical time

- $t_{q j}$ Average time parts spend behind machine $j$

- $t$ Critical waiting time

- $n p_{i}$ Total number of part $i$ 
Table 2 Abbreviations used in Table 1

\begin{tabular}{|c|c|c|c|c|c|}
\hline Objective function & Abbreviation & Problem definition & Abbreviation & Solution and outputs & Abbreviation \\
\hline $\begin{array}{l}\text { Inter-cell material handling } \\
\text { cost }\end{array}$ & INTER & Single objective & SO & Branch and bound & $B \& B$ \\
\hline $\begin{array}{l}\text { Intra-cell material handling } \\
\text { cost }\end{array}$ & INTRA & Multi-objective & $\mathrm{MO}$ & Branch and cut & $B \& C$ \\
\hline Machine operating cost & OC & Combined objective & $\mathrm{CO}$ & Genetic algorithm & GA \\
\hline Material moves & MM & Multi-criteria & $M C$ & Decomposition base heuristic & $\mathrm{DBH}$ \\
\hline Backorder cost & $\mathrm{BC}$ & Multi-period planning & MPP & Silver meal heuristic & $\mathrm{SMH}$ \\
\hline Production cost & PC & Stochastic problem & STP & Tabu search & TS \\
\hline Inventory cost & IC & Dynamic programming & DP & Hierarchical genetic algorithm & AGA \\
\hline Reconfiguration cost & $\mathrm{RCC}$ & Integer program & IP & $\begin{array}{l}\text { Mean field annealing and simulated } \\
\text { annealing }\end{array}$ & MFA-SA \\
\hline Capital investment & $\mathrm{Cl}$ & Mixed integer program & MIP & Multi-objective scatter search & MOSS \\
\hline Machine holding cost & $\mathrm{MHC}$ & Non-linear program & NLP & Hierarchical approach & HIA \\
\hline System setup cost & SC & $\begin{array}{l}\text { Mixed integer non-linear } \\
\text { program }\end{array}$ & MINLP & CB procedure & CBP \\
\hline Dissimilarity between parts & DS & $\begin{array}{l}\text { Quadratic assignment } \\
\text { problem }\end{array}$ & QAP & Particle swarm optimization & PSO \\
\hline Cell load variation & CLV & $\begin{array}{l}\text { Two-stage scheduling } \\
\text { problem }\end{array}$ & $2 S P$ & Scatter search & SS \\
\hline Extra capacity requirement & ECR & & & Neural approach & NA \\
\hline Total distance traveled & TDT & & & Cell formation & CF \\
\hline Cell setup cost & CSC & & & Inventory level & IL \\
\hline Holding cost & $\mathrm{HC}$ & & & Production level & $P L$ \\
\hline Machine cost & $M C$ & & & Backorder level & $B L$ \\
\hline Machine amortization cost & MAC & & & Reconfiguration plan & $\mathrm{RCP}$ \\
\hline Machine breakdown cost & $\mathrm{MBC}$ & & & Machine sequence & MSE \\
\hline Failure rate of machine & FRM & & & Cell size & CS \\
\hline Machine variable cost & VCM & & & Group layout & $\mathrm{GL}$ \\
\hline Machine constant cost & CCM & & & Process route & PR \\
\hline $\begin{array}{l}\text { Machine non-utilization } \\
\text { cost }\end{array}$ & NUC & & & Machine duplication & MD \\
\hline Total number of voids & VO & & & Production plan & PP \\
\hline Total exceptional elements & $\mathrm{EE}$ & & & Production scheduling & PS \\
\hline Completion time & CM & & & Processing part requirement & PRP \\
\hline Inverse of system reliability & ISR & & & Optimal preventive maintenance interval & OPMI \\
\hline Purchase cost of machine & PUC & & & Subcontracted quantity & SBQ \\
\hline $\begin{array}{l}\text { Preventive maintenance } \\
\text { cost }\end{array}$ & PM & & & Worker assignment & WA \\
\hline Sub-contracting cost & SCC & & & & \\
\hline Inventory transportation & IT & & & & \\
\hline Intra-cell move time & INTRAT & & & & \\
\hline Tardiness time & $\pi$ & & & & \\
\hline Salary cost & SAC & & & & \\
\hline Firing cost & $\mathrm{FIC}$ & & & & \\
\hline
\end{tabular}


Table 2 Abbreviations used in Table 1 (Continued)

\begin{tabular}{ll}
\hline Hiring cost & HIC \\
Process routes setup cost & PRS \\
Corrective repair cost & CRC \\
Machine idleness cost & ICM
\end{tabular}

- $C_{u}$ Maximum number of cells

- $\lambda_{i} \quad$ Mean arrival rate for part $i$

- $\mu_{j} \quad$ Mean service rate for machine $j$

- $U_{i j} \quad$ Cost of part $i$ not utilizing machine $j$

- $h_{i}$ Holding cost per unit for part $i$

\section{Decision variables}

The following are the decision variables:

- $\quad X_{i k}=\left\{\begin{array}{l}1 \text { if part } i \text { is assigned to cell } k \\ 0 \text { otherwise }\end{array}\right.$

- $\quad Y_{j k}=\left\{\begin{array}{l}1 \text { if machine } j \text { is assigned to cell } k \\ 0 \text { otherwise }\end{array}\right.$

- $\rho_{j}$ Utilization factor for machine $j$ (the value of $\rho$ indicates the probability in which machine $j$ is busy)

\section{Mathematical model}

In this section, details of the mathematical formulation which we are interested will be described. For this purpose, the following formulations are presented:

$$
\begin{aligned}
\operatorname{Min} Z & =\sum_{j}\left(1-\rho_{j}\right) u_{j}+\sum_{k} \sum_{j} \sum_{i} C_{i} a_{i j} X_{i k}\left(1-Y_{j k}\right) \\
& +\sum_{k} \sum_{j} \sum_{i} U_{i j} X_{i k} Y_{j k}\left(1-a_{i j}\right) \\
& +\sum_{k} \sum_{j} \sum_{i} \frac{h_{i} a_{i j} X_{i k} Y_{j k}}{n p_{i}}
\end{aligned}
$$

subject to

$$
\begin{aligned}
& \sum_{k} X_{i k}=1 \quad i=1,2, \ldots, p, \\
& \sum_{k} Y_{j k}=1 \quad j=1,2, \ldots, m, \\
& \rho_{j}-\sum_{k} \frac{\sum_{i} \lambda_{i} a_{i j} X_{i k} Y_{j k}}{\mu_{j}}=0 \quad j=1, \ldots, m, \\
& \sum_{j} Y_{j k} \leq M_{m} \quad k=1,2, \ldots, c, \\
& P\left(t_{q j}>t\right) \leq \alpha, \\
& \rho_{j} \leq 1 j=1,2, \ldots, m, \\
& X_{i k}, Y_{j k} \in\{0,1\}, \rho_{j} \geq 0 .
\end{aligned}
$$

Equation 1 indicates the objective function which can compute the total idleness cost for machines in cells, sub-contracting cost, resource underutilization cost, and holding cost of parts in cells. Set constraint (2) restricts that each part is allocated to only one cell. Set constraint (3) ensures that each machine is allocated to only one cell. Set constraint (4) computes the utilization factor. Set constraint (5) guarantees that the number of machines in each cell will not exceed the maximum number. Equation (6) is a chance constraint and ensures that the probability that the average waiting time of parts behind each machine exceeds the critical time is less than the service level $(\alpha)$. Set constraint (7) says that the proportion of time that the machine is processing a part must be less than or equal to 1 . Set constraint (8) specifies binary and non-negative variables.

\section{Linearization of the model}

As the objective function has non-linear terms, we can change it to a mixed integer linear programming. For this purpose, we replace a new binary variable $Z_{i j k}$ instead of the multiple of $X_{i k}$ and $Y_{j k}$. We reformulate the model, and the three auxiliary constraints (10), (11), and (12) are added to the model to guarantee the correctness of the replacement. Constraint (6) is equal to $e^{-\mu_{j}\left(1-\rho_{j}\right) t} \leq$ $\alpha$ and contains a non-linear equation; therefore, Equation 14 denotes the linear form of this constraint.

$$
\begin{aligned}
\operatorname{Min} Z & =\sum_{j}\left(1-\rho_{j}\right) u_{j}+\sum_{k} \sum_{j} \sum_{i} C_{i} a_{i j} X_{i k} \\
& -\sum_{k} \sum_{j} \sum_{i} C_{i} a_{i j} Z_{i j k} \\
& +\sum_{k} \sum_{j} \sum_{i} U_{i j}\left(1-a_{i j}\right) Z_{i j k} \\
& +\sum_{k} \sum_{j} \sum_{i} \frac{a_{i j} Z_{i j k}}{n p_{i}} .
\end{aligned}
$$

Subject to constraints (2), (3), (5), (7), and (8),

$$
\begin{aligned}
& Z_{i j k} \leq X_{i k} \forall i, j, k, \\
& Z_{i j k} \leq Y_{j k} \forall i, j, k, \\
& X_{i k}+Y_{j k}-Z_{i j k} \leq 1 \forall i, j, k .
\end{aligned}
$$

Constraints (4) and (6) are changed as follows:

$$
\begin{aligned}
& \rho_{j}-\sum_{k} \frac{\sum_{i} \lambda_{i} a_{i j} Z_{i j k}}{\mu_{j}}=0 \quad \forall j \\
& -\mu_{j}\left(1-p_{j}\right) t \leq \ln \alpha \forall j .
\end{aligned}
$$


Table 3 Effectiveness of queuing approach in a CMS problem

\begin{tabular}{|c|c|c|c|c|c|}
\hline \multicolumn{6}{|c|}{ Problem information } \\
\hline $\begin{array}{l}\text { Problem } \\
\text { number }\end{array}$ & $\begin{array}{l}\text { Number of parts } \times \text { number of } \\
\text { machines } \times \text { number of cells }\end{array}$ & $\begin{array}{l}\text { Maximum number of machine } \\
\text { allowed in each cell }\end{array}$ & $\begin{array}{l}\text { Idleness } \\
\text { rate cost }\end{array}$ & $\begin{array}{l}\text { Average } \\
\text { utilization factor } \\
\text { (\%) }\end{array}$ & $\begin{array}{l}\text { Number of inter- } \\
\text { cellular movement }\end{array}$ \\
\hline P1 & $30 \times 10 \times 3$ & 4 & 300 & 24.27 & 43 \\
\hline P2 & & & 460 & 31.27 & 40 \\
\hline P3 & & & 654 & 34.66 & 38 \\
\hline P4 & & & 850 & 44.52 & 32 \\
\hline P5 & & & 905 & 48.36 & 30 \\
\hline P6 & & & 1,025 & 56.83 & 25 \\
\hline P7 & & & 1,350 & 59.90 & 21 \\
\hline P8 & & & 1,600 & 62.05 & 20 \\
\hline P9 & & & 2,105 & 65.12 & 16 \\
\hline P10 & & & 2,678 & 69.97 & 13 \\
\hline P11 & $38 \times 10 \times 3$ & 4 & 300 & 46.91 & 52 \\
\hline P12 & & & 460 & 47.56 & 51 \\
\hline P13 & & & 654 & 48.55 & 50 \\
\hline P14 & & & 850 & 48.64 & 50 \\
\hline P15 & & & 905 & 48.71 & 49 \\
\hline P16 & & & 1,025 & 48.93 & 49 \\
\hline P17 & & & 1,350 & 49.63 & 49 \\
\hline P18 & & & 1,600 & 49.80 & 48 \\
\hline P19 & & & 2,105 & 49.96 & 48 \\
\hline P20 & & & 2,678 & 50.25 & 48 \\
\hline
\end{tabular}

\section{Experimental results}

Consider a manufacturing system consisting of ten machines to process parts, wherein the decision maker should allocate machines and parts to three cells. Also, the maximum number of machines permitted to be located is four. In this section, we present some numerical examples which have been generated randomly, to illustrate the effect of changing the main parameters $(\alpha, t$, $u_{j}$ ), on the number of sub-contracting movements and utilization factors. The proposed mixed integer model was performed by GAMS and Cplex solver and was run on a processor Intel Core 2 Duo CPU running at $2 \mathrm{GHz}$ with 2-GB RAM.

In Table 3, the results associated to solve two sets of examples for ten times for each is shown, where only idleness cost is not fix, and the impact of its changes on the average utilization factor and the number of subcontracting movements are illustrated. As the utilization factor of the machines is directly related to the idleness cost, it can be found that the more the average of

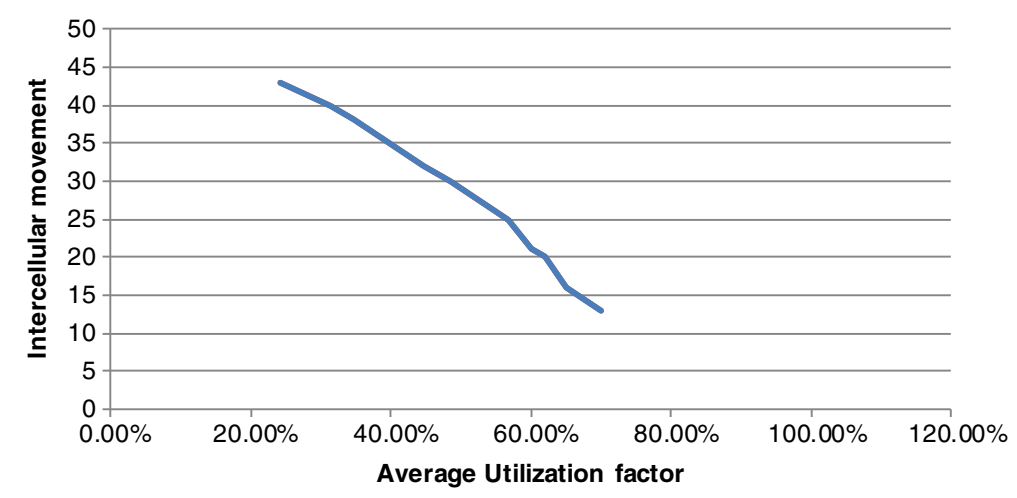

Figure 1 Relationship curve between average utilization factor and number of sub-contracting movements of set problem 1. 


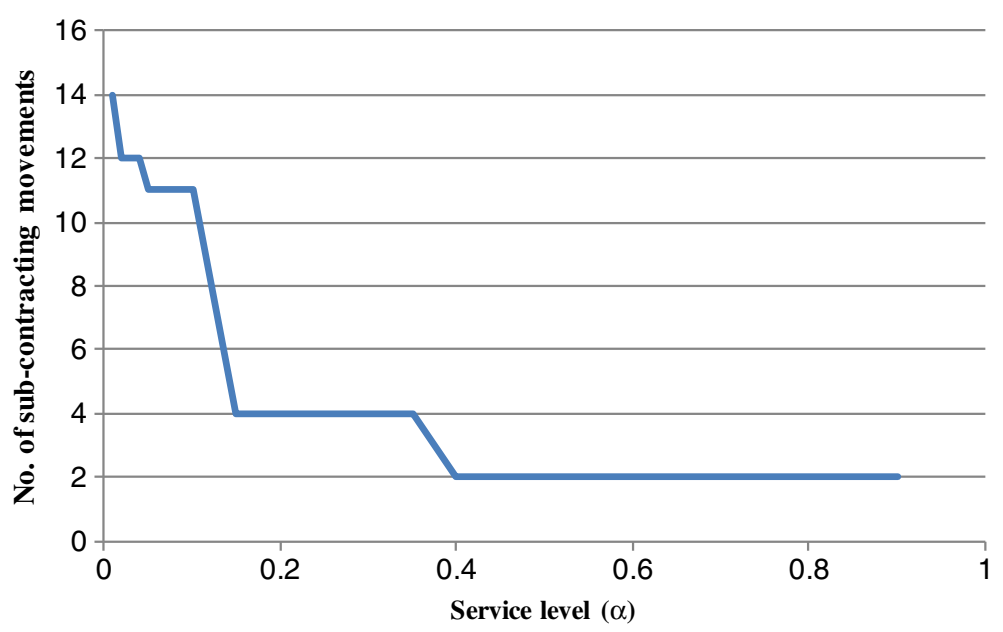

Figure 2 Relationship curve between service level and number of sub-contracting movements.

idleness cost leads to the better design of cellular manufacturing system. It means more costs lead to a higher utilization factor. Also, more utilization factor may lead to less number of sub-contracting movements. Results of both sets show the same changes.

Figure 1 indicates the relation between the average utilization factor and number of sub-contracting movements of set problem 1 . It can be found that by increasing idleness cost, the average utilization factor will be increased, too. As the term $\Sigma\left(1-\rho_{j}\right) u_{j}$ indicates, the direct relation between idleness cost and utilization factor is established. Therefore, in order to minimize this term, by increasing idleness cost, idleness rate of machine must be decreased. This means that the probability that each machine is busy increases. Therefore, the total number of sub-contracting movements must be decreased in order to decrease idleness of each machine. The less total number of sub-contracting movements makes the queue system be more populated. Therefore, the total objective function value will be minimized.

The effect of service level's changes (the maximum allowed probability that the waiting time behind each machine can be more than the critical time) on the subcontracting movements is shown in Figure 2. This figure illustrates that for a fixed critical waiting time, if the service level $(\alpha)$ increases, the upper bound of utilization factor $\left(\rho_{j}\right)$ will increase, where this growth may cause decreasing in the total number of sub-contracting movements.

Figure 3 demonstrates the relation between changes of critical waiting time and number of sub-contracting movements. If we assume all the parameters to be fixed except the service level $(\alpha)$, increasing the critical waiting time may lead to the reduction of the number of sub-contracting movements, which is due to the increase of the upper bound of the utilization factor.

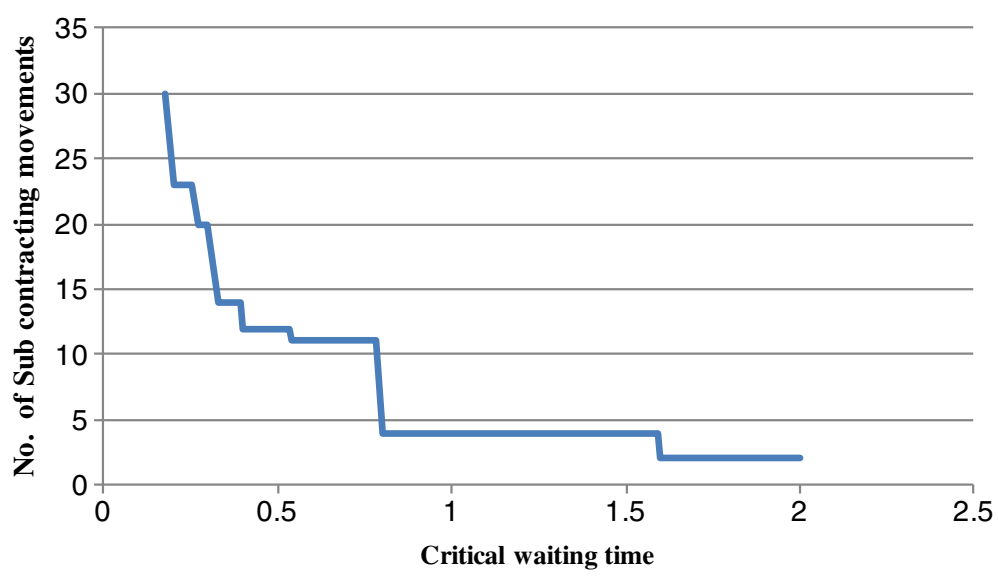

Figure 3 Relationship between critical waiting time and number of sub-contracting movements. 


\section{Conclusions and future directions}

We have developed a stochastic CMS model that considers the arrival rate of parts into cells and machine service rate as uncertain parameters. The proposed nonlinear mixed integer programming model was linearized using auxiliary variables. Then, the linearized model was solved using the Cplex solver of GAMS. As the CMS problem is NP-hard, by increasing the size of the problem, GAMS stops solving it; due to the increase of computational time, the branch-and-cut algorithm is unable to give good solutions. Therefore, it is necessary to present a heuristic or meta-heuristic approach to solve this model for large-scale problems. Also, the following directions can be applied for further considerations:

1. Developing the proposed model under new stochastic parameters such as capacities, lead times, and machine failures.

2. Analyzing the defined problem under scenario-based planning approach and robust optimization theory.

3. Incorporating our objectives with productivity and production planning aspects in uncertain situations.

\section{Competing interests}

The authors declare that they have no competing interests.

\section{Authors' contributions}

VG carried out the modeling, drafted the manuscript, involved in revising the manuscript, and gave final approval of the version to be published. FF was involved in performing the model and analyzing the results, participated in the sequence alignment, and helped draft the manuscript. AZ carried out the literature study and participated in the design of the study and the sequence alignment. All authors read and approved the final manuscript.

\section{Author details}

IIslamic Azad University, South Tehran Branch, Tehran, Iran. ${ }^{2}$ Faculty of Industrial Engineering, Islamic Azad University, South Tehran Branch, Tehran, Iran.

Received: 21 May 2013 Accepted: 21 May 2013

Published: 15 July 2013

\section{References}

Ariafar SH, Ismail N, Tang SH, Ariffin MKAM, Firoozi Z (2011) A stochastic facility layout model in cellular manufacturing systems. International Journal of the Physical Sciences 6(15):3666-3670

Bajestani AM, Rahimi-Vahed AR, Khoshkhou BG (2009) A multi-objective scatter search for a dynamic cell formation problem. Comp Oper Res 36(3):777-794

Baykasoglu A, Gindy NNZ, Cobb RC (2001) Capability based formulation and solution of multiple objective cell formation problems using simulated annealing. Integr Manuf Syst 12(4):258-274

Cesani VI, Steudel HJ (2005) A study of labor assignment flexibility in cellular manufacturing systems. Comp Indust Eng 48(3):571-591

Chan FFS, Lan KW, Chan PLY, Choy KLL (2006) Two stage approach for machine part grouping and cell layout problem. Robot Comp Integr Manuf 22(3):217-238

Chen M (1998) A mathematical programming model for system reconfiguration in a dynamic cellular manufacturing environment. Ann Oper Res 77:109-128

Chen M (2001) A model for integrated production planning in cellular manufacturing systems. Integr Manuf Syst 12(4):275-284

Das K, Lashkari RS, Sengupta S (2006) Reliability considerations in the design of cellular manufacturing systems: a simulated annealing based approach. Int Qual Reliability Manage 23(7):880-904
Das K, Lashkari RS, Sengupta S (2007) Machine reliability and preventive maintenance planning for cellular manufacturing system. Eur J Oper Res 183 (1):162-180

Jabal-Ameli MS, Arkat J (2007) Cell formation with alternative process routings and machine reliability consideration. Int J Adv Manuf Technol 35(7):761-768 Kioon SA, Bulgak AA, Bektas T (2009) Integrated cellular manufacturing system design with production planning and dynamic system reconfiguration. European Journal of Operation Research 192(2):414-428

Logendran R (1993) Methodology for converting a functional manufacturing system into a cellular manufacturing system. Int J Prod Econ 29(1):27-41

Mahdavi I, Mahadevan B (2008) CLASS: an algorithm for cellular manufacturing system and layout design using sequence data. Robot Comp Integr Manuf 24(3):488-497

Mahdavi I, Javadi B, Fallah-Alipour K, Slomp J (2007) Designing a new mathematical model for cellular manufacturing system based on cell utilization. App Math Comput 190(1):662-670

Mahdavi I, Alaei A, Paydar MM, Solimanpour M (2010) Designing a mathematica model for dynamic cellular manufacturing systems considering production planning and worker assignment. Comp Math Appl 60(4):1014-1025

Mak KL, Wang XX (2002) Production scheduling and cell formation for virtual cellular manufacturing system. Int J Adv Manuf Technol 20(2):144-152

Muruganandam A, Prabharan G, Asokan P, Baskaran V (2005) A memetic algorithm approach to the cell formation problem. Int J Adv Manuf Technol 25:988-997

Olorunniwo F, Udo G (2002) The impact of management and employees on cellular manufacturing implementation. Int J Prod Econ 76(1):27-38

Rafiee K, Rabbani M, Rafiei H, Rahimi-Vahed A (2011) A new approach towards integrated cell formation and inventory lot sizing in an unreliable cellular manufacturing system. Appl Math Modeling 35(4):1810-1819

Safaei N, Tavakkoli-Moghaddam R (2009) Integrated multi-period cell formation and sub-contracting production planning in dynamic cellular manufacturing system. Int J Prod Econ 120(2):301-314

Safaei N, Saidi-Mehrabad M, Jabal-Ameli MS (2008) A hybrid simulated annealing for solving an extended model for dynamic cellular manufacturing system. Eur J Oper Res 185(2):563-592

Saidi-Mehrabad M, Ghezavati VR (2009) Designing cellular manufacturing system under uncertainty. J Uncert Syst 3(4):315-320

Saidi-Mehrabad M, Safaei N (2007) A new model of dynamic cell formation by a neural approach. Int J Adv Manuf Technol 33:1001-1009

Sarker BR, Li K (1997) Simultaneous route selection and cell formation: a mixedinteger programming time-cost model. Integr Manuf Syst 8(6):374-377

Schaller J (2007) Designing and redesigning cellular manufacturing system to handle demand change. Comput Ind Eng 53(3):478-490

Tavakkoli-Moghaddam R, Aryanezhad MB, Safaei N, Azaran A (2005) Solving a dynamic cell formation problem using meta-heuristics. Appl Mathe Comp 170(2):761-780

Tavakkoli-Moghaddam R, Javadian N, Javadi B, Safaei N (2007) Design of facility layout problem in cellular manufacturing system with stochastic demand. Appl Math Comput 184(2):721-728

Tavakkoli-Moghaddam R, Javadian N, Khorrami A, Gholipor-Kanani Y (2010) Design of a scatter search method for a novel multi-criteria group scheduling problem in a cellular manufacturing system. Expert Syst Appl 37 (3):2661-2669

Wemmerlov U, Hyer NL (1989) Cellular manufacturing in the U.S. industry: a survey of users. Int J Product Res 27(9):1511-1530

Wicks EM, Reasor RJ (1999) Designing cellular manufacturing systems with dynamic part populations. Inst Indust Eng Trans 31(1):11-20

Wu X, Chu CH, Wang Y, Yan W (2007a) A genetic algorithm for cellular manufacturing design and layout. European J Oper Res 181(1):156-167

Wu X, Chu CH, Wang Y, Yue D (2007b) Genetic algorithm for integrating cell formation with machine layout and scheduling. Comp Indust Eng 53(2):277-289

Yasuda K, Hu L, Yin Y (2005) A grouping genetic algorithm for the multiobjective cell formation problem. Int J Prod Res 43(4):829-853

doi:10.1186/2251-712X-9-20

Cite this article as: Fardis et al: Stochastic extension of cellular manufacturing systems: a queuing-based analysis. Journal of Industrial Engineering International 2013 9:20. 